\section{Seeking a Rapprochement Between Anthropology and the Cognitive Sciences: A Problem-Driven Approach}

\author{
Harvey Whitehouse, ${ }^{\mathrm{a}}$ Emma Cohen ${ }^{\mathrm{b}}$

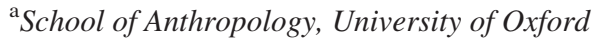 \\ ${ }^{\mathrm{b}}$ Comparative Cognitive Anthropology Research Group, Max Planck Institute for Psycholinguistics, Max Planck \\ Institute for Evolutionary Anthropology
}

Received 7 July 2011; received in revised form 9 November 2011; accepted 5 December 2011

\begin{abstract}
Beller, Bender, and Medin question the necessity of including social anthropology within the cognitive sciences. We argue that there is great scope for fruitful rapprochement while agreeing that there are obstacles (even if we might wish to debate some of those specifically identified by Beller and colleagues). We frame the general problem differently, however: not in terms of the problem of reconciling disciplines and research cultures, but rather in terms of the prospects for collaborative deployment of expertise (methodological and theoretical) in problem-driven research. For the purposes of illustration, our focus in this article is on the evolution of cooperation.
\end{abstract}

Keywords: Anthropology; Cultural evolution; Cooperation; Synchrony; Ritual; Arousal

\section{Introduction}

According to Beller and colleagues "the problems between anthropology and the other cognitive science sub-disciplines ... are deep-so deep in fact, that a separation, if not an outright divorce, may be called for." Presumably, however, this bleak conclusion is not intended to encompass all research traditions in anthropology. Consider the case of cognitive anthropology, a rather dowdy bride perhaps, preoccupied in her youth with matters of limited consequence, such as the relativity of color terminology, kinship taxonomy, or spatial cognition (D'Andrade, 1995). Cataloguing such variability was no doubt a respectable pursuit, placing traditional cognitive anthropology in an obedient if somewhat lowly position in the harem of the cognitive sciences. Clearly, the relations between academic disciplines do not need to be marriages made in heaven in order to function well. Social or

Correspondence should be sent to Emma Cohen, Max Planck Institute for Psycholinguistics, Wundtlaan 1, Nijmegen, The Netherlands. E-mail: emma_cohen@eva.mpg.de 
cultural anthropology is an older and more dominant partner. She may be stubborn, cantankerous, and uncooperative but she commands bodies of knowledge that are needed to tackle problems at the heart of the social, biological, and cognitive sciences. A good example is the problem of explaining cooperation in large groups.

Cooperation has been shown to play a crucial role in the reproduction of genes, cells, organisms, and groups of organisms, to the extent that it has even been described as the third fundamental principle of evolution, alongside mutation and selection (Nowak, 2006). Explaining how cooperation evolves has been a major focus in the biological sciences for more than half a century, prompting some of the most influential concepts in evolutionary thinking, including kin selection and the extended phenotype (Dawkins, 1976; Hamilton, 1964), reciprocity and altruism (Axelrod, 1984), and multilevel selection (Michod, 1999). Some of these concepts are particularly important for understanding human psychology and behavior and the evolution of cultural systems. Adapting Dobzhansky's famous phrase, it has recently been observed that nothing in psychology makes sense except in the light of evolution (Bjorklund, 2011), but it could equally be said that nothing in social science makes sense except in the light of cooperation.

Broadly we can distinguish two kinds of explanatory challenges with regard to cooperation in human societies. First, there is the challenge of explaining the evolution of specialized cognitive architecture supporting cooperative behavior in our species. Experimental psychologists and game theorists have made significant progress investigating the mechanisms that underpin cooperation among individuals, such as prosocial and antisocial punishment, social identification, fusion, social learning, empathizing, and coalitional thinking. All these mechanisms evolved under natural selection when our ancestors hunted and foraged in small, face-to-face groups. Second, there is the challenge of explaining the evolution of cultural mechanisms supporting a diversity of forms of cooperation from generalized reciprocity in hunter-gatherer bands to complex systems of top-down regulation in stratified states. Such diversity constitutes the heartland of social anthropology's subject matter.

Ethnographers have documented principles of cooperation at work in a wide range of domains, including kinship, marriage and descent, legal institutions and political organization, religious thinking and behavior, and techniques of production, consumption, and exchange. This empirical wealth and the general questions that prompted its assembly constitute an obvious starting point for scientifically rigorous investigation of the evolution of cooperation in human societies. No serious biologist would by choice launch an investigation into the psychology and behavior of a new species based on its behavior in a cage or tank but would instead begin with painstaking observation in a range of natural environments. We would argue that anthropology should be to the cognitive sciences what fieldwork is to experimental primatology. It is a starting point for the production of testable hypotheses.

\section{The cognitive science of cooperation}

The varieties of human cooperative behaviors that have been described and accounted for by ethnographers, ecologists, and evolutionary biologists rely on a range of psychological 
mechanisms. Identifying and describing the skills and motivations that enable human cooperation is a core challenge for cognitive science, and distinct from explaining why and how these mechanisms evolved. Here, we specifically focus on the importance of behavioral synchrony as a causal mechanism enabling uniquely human cooperation and social bonding. As with established themes in cooperation literature, such as kin selection and nepotism, and reciprocity and exchange, this growing area of research has emerged from the interdisciplinary engagement of anthropological, cognitive, and evolutionary scholarship.

In sociology and anthropology, group synchronous activity has long been recognized as an integral and universal component of human social life (Kertzer, 1989). Dancing, singing, chanting, drumming, and group music-making require careful coordination and synchrony among participants, and they are often the focus of intense social events and experiences. In his treatment of ritual, anthropologist Victor Turner developed the influential concept of communitas to refer to the bond of "humankindness" among participants and its accompanying affect (1969). Turner defined communitas metaphorically as "the 'quick' of human relatedness," evoking Emile Durkheim's notion of "collective effervescence," which also described the intense feelings of bondedness and "moral unity" among participants in sacred ritual (2001, p.175). For Durkheim and Turner, communal ritual activities could serve to weaken the boundaries between self and the group, and generate a community sense of "unprecedented potency." Despite the influence of these concepts and insights on the subsequent development of anthropological theory, their potential importance for explanatory accounts of human cooperation has remained obscure. How do ceremonies breed "moral unity," if at all? What features engender a sense of community? Are these features present beyond the religious or ritual domain?

Recently, the bonding effects of synchronous communal activity have received increasing attention in the cognitive scientific literature on cooperation. Following Durkheim's lead, several researchers have explored the hypothesis that behavioral synchrony enhances social cohesion and cooperation. Using standard behavioral economics measures, Wiltermuth and Heath (2009) showed that coordinated synchronous walking or marching has a significant positive effect on cooperation (compared to merely walking together). Hove and Risen (2009) found that synchronous dyadic finger tapping had a significant positive influence on subsequent affiliation ratings between participants (compared to non-synchronous tapping). Developmental research suggests that the capacity for synchronous music-making to enhance cooperation emerges early in childhood. Kirschner and Tomasello (2010), for example, found that 4-year-old children were more likely spontaneously to provide instrumental help and cooperate in a problem-solving task with a partner after a performance entailing coordinated synchrony.

Although this research has given some empirical weight to early theoretical speculations, it is still not clear precisely how the synchrony mechanism works. How does synchronous activity influence social cohesion and cooperation? Three distinct but potentially complementary mechanisms have been advanced.

1. Cohen, Ejsmond-Frey, Knight, and Dunbar (2010) stress the role of opioidergic activity in physical exercise, claiming that group synchronous exercise enhances endorphin 
activity and associated feelings of well-being. Compared to solo rowing, they found that synchronized group rowing significantly heightened pain threshold (an indirect measure of endorphin release), providing support for the hypothesis that the feel-good release of endorphins underpins the positive influence of synchrony on social bonding and cooperation, including participants' willingness to behave altruistically.

2. Hove and Risen (2009) and Miles, Nind, Henderson, and Macrae (2010) consider an interpretation in terms of self-other representation. In highly synchronous activity, perceptions of self- versus other-produced action closely overlap. This effectively blurs the self-other distinction, potentially heightening feelings of closeness and mutual understanding. Positive views of self extend to the other, thus enhancing affiliation.

3. Kirschner and Tomasello (2010) emphasize the importance of collective intentions and shared goals in the generation of coordinated, synchronous activity and subsequent altruistic and cooperative behavior among participants. The high level of coordination and constant audio-visual representation of the collective intention and goal to vocalize or move together strengthens participants' sense that they are acting together as a unit.

Some theorists have proposed that the synchrony effect, however it works, potentially accounts for the widespread appeal and incidence of cultural rituals involving synchronous activity such as singing, dancing, marching, and drumming. Nevertheless, many such issues at anthropology's heartland remain largely unexplored. Future cognitive scientific research on ritualized synchrony-its cross-cultural incidence, the cultural (and biological) evolution of mechanisms permitting and promoting it, and its purported social bonding function within groups (as well as its potential, in turn, to contribute to hostility and conflict between groups) - will necessarily require systematic scrutiny of the ethnographic record and the generation of relevant new ethnographic data. For the problem of synchrony, and the problem of cooperation more generally, continued collaboration among experts across the biological, cognitive, and social sciences_-including anthropology-will be necessary for further progress in answering critical questions about ultimate purposes and proximate mechanisms.

\section{The cultural evolution of cooperation}

Until the start of the Holocene, the limits of human cooperation ran to hundreds of individuals and rarely more than a thousand. And yet nowadays most of the world's population is enfolded into coalitions that command allegiance from millions of individuals governed by the holders of permanent offices according to codified rules applying within and across numerous levels of jurisdictional hierarchy. In this section, we ask how the scale and structure of human cooperation crossed the evolutionary threshold separating small egalitarian bands from large-scale systems of top-down control.

As noted in Section 2, rituals can help to bind people together and promote cooperation. Anthropologists have long observed, however, that there are two main kinds of group 
cohesion: the one small-scale uniting face-to-face communities and the other large-scale uniting "imagined communities" (Whitehouse, 1995). The theory of modes of religiosity (hereafter "the modes theory"') proposes that these divergent patterns of group formation are a consequence of the frequency and emotionality of ritual performances (Whitehouse, 1995, 2000, 2004). According to this theory, low-frequency, dysphorically arousing rituals (e.g., painful or frightening initiation rituals) generate intense cohesion in small groups through the activation of a series of closely related psychological mechanisms summarized below. This syndrome, prevalent in many small-scale societies and local cults, is labeled the "imagistic mode", on account of the fact that participants reflect on their ritual ordeals, producing a wealth of imagery and interpretation. By contrast, high-frequency, low-arousal rituals sustain standardized bodies of teaching and practice efficiently spread across large populations, enabling the establishment of large group identities and the emergence of priestly hierarchies. This syndrome, prevalent in the world religions and many large regional movements, is labeled the "doctrinal mode" because of its emphasis on the maintenance of doctrinal orthodoxy.

One of the core predictions of the modes theory is that the lowest frequency rituals will typically involve the highest levels of dysphoric arousal and that high-frequency rituals will seldom entail high levels of dysphoria. Initial efforts to test the modes theory against a range of case studies presented by ethnographers and historians (Whitehouse \& Martin, 2004). But these case studies were not randomly selected. To avoid the risk of "cherry picking," an ethnographic database of 644 rituals taken from a sample of 74 language groups was constructed using evidence stored in the Human Relations Area Files (HRAF: a large collection of ethnographic writings). For each ritual nearly 100 variables were recorded as present, absent, or not reported or coded on a scale from 1 to 5 . The database included details of the scale and structure of ritual communities and various aspects of ritual frequency and emotional arousal. Also included were numerous other variables relating to more detailed predictions of the modes theory. It was possible to construct such a detailed database only because ethnographers had gone to the trouble of documenting the features of interest at least partly as a consequence of theoretical frameworks summarized in Section 2. Here we report just a few of our findings (from Atkinson \& Whitehouse, 2010).

Fig. 1 shows that frequency and arousal are inversely correlated, as predicted by the modes theory. More specifically, it reveals that in the lowest frequency rituals dysphoric arousal rises in intensity, whereas euphoric arousal peaks around annual frequency. Moreover, the heat maps in Fig. 2 reveal that this is not simply an inverse correlation between frequency and arousal since there is a heavy clustering of low-arousal rituals at the high-frequency end and of dysphoric rituals at the low-frequency end of the spectrum. This is consistent with the idea that doctrinal and imagistic modes are best understood as divergent attractor positions rather than a continuum of possibilities. Importantly, this study revealed that groups with high-frequency/low-arousal rituals tend to be much larger than groups with low-frequency/dysphoric rituals. Moreover, a significant correlation was found between high-frequency ritual and the presence of agriculture even controlling for the effects of world religions. This suggests that the transition from foraging to farming may have been accompanied by an increase in the pace of ritual life and thus a shift from imagistic to doctrinal dynamics. 

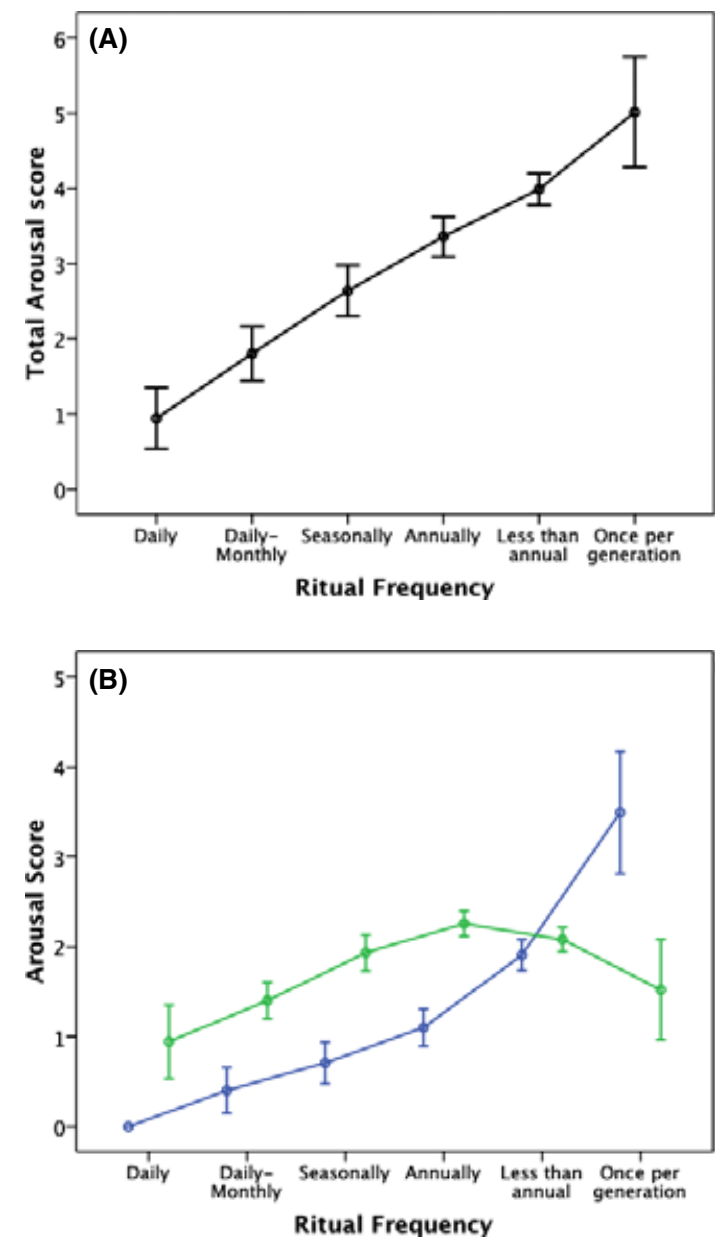

Fig. 1. A: Arousal scores by ritual frequency (rho $=0.401, n=644, p<.001)$. B: Arousal scores by ritual frequency for euphoric (green; rho $=0.08, n=644, p<.05$ ) and dysphoric (blue; rho $=0.409, n=644, p<.001$ ) arousal (from Atkinson \& Whitehouse, 2010).

To investigate further this last possibility requires close scrutiny of the archeological evidence (Johnson, 2004; Mithen, 2004; Whitehouse \& Hodder, 2010). Preliminary studies at one site of first emergence of crop cultivation and animal domestication, the Neolithic excavations at Catalhoyuk (Central Anatolia, Turkey), shows evidence of low-frequency feasting events in the faunal remains and wall paintings suggest that these feasts involved elaborate and dangerous rituals which included the baiting of very large wild animals. By the end of the period of settlement, however, these practices appear to have largely died out. Hunting is gradually replaced by farming, and much larger communities encompassing thousands of individuals emerge along with more discursive forms of religiosity. Thus, initial indications suggest there was indeed a shift from imagistic to doctrinal modes of religiosity (Whitehouse \& Hodder, 2010). To test these claims more systematically, many thousands of 

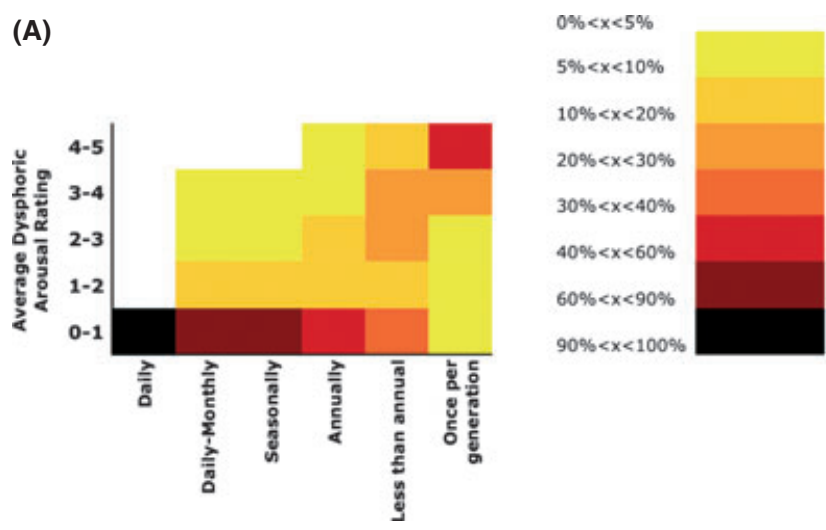

(B)

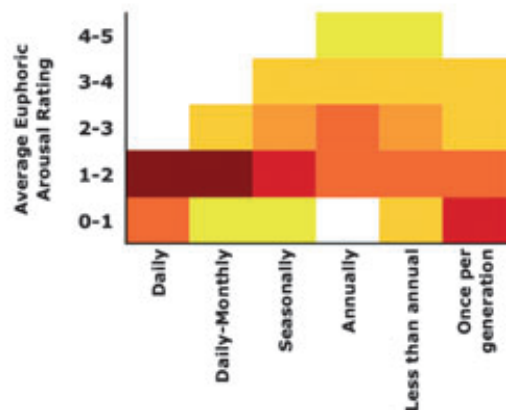

Fig. 2. Heat map of dysphoric (A) and euphoric (B) arousal score versus ritual frequency $(n=644)$ (from Atkinson \& Whitehouse, 2010).

findings at Catalhoyuk are currently being recoded using the same format as our HRAF database so that we will be able to analyze the relationship between ritual frequency and arousal and changing group morphology over nearly 2,000 years of settlement at the site.

Statistical methods of this kind can provide a detailed picture of the correlates of target variables, such as different scales of coalition formation and intensities of group cohesion. But correlations are not the same as causes. To disambiguate the psychological mechanisms that give rise to these patterns requires carefully controlled experiments. Efforts to test the predictions of the modes theory experimentally have focused on the causal opacity of ritual (the absence of a knowable physical-causal relationship between procedures and end-goals) and the effects of this on exegetical innovation and transmission, which are thought to be mediated by emotional arousal. Of particular note, recent studies with young children at the University of Texas at Austin have shown an early developing propensity to imitate causally opaque procedures with greater rigidity, and to be less inclined to innovate, when end-goals are lacking (Legare and Whitehouse, unpublished data). Readiness to learn behaviors that have no rational causal structure facilitates the spread of rituals, socially prescribed procedures that signal group identity without necessarily effecting changes in the physical environment. Experimental manipulation of emotional arousal during the performance of causally opaque actions has meanwhile been shown to moderate the volume and specificity of subsequent reflection on the meanings of the actions, which is thought to affect the intensity of in-group cohesion (Richert, Whitehouse, \& Stewart, 2005). A 5 year program of research on the modes theory starting in June 2011 is building on these findings through more systematic studies of the cognitive underpinnings and social consequences of ritual by combining qualitative anthropological studies with psychological experiments, quantitative surveys, and computational modeling techniques (http://www.cam.ox.ac.uk/ritual/). This kind of cross-disciplinary research spans the cognitive and evolutionary sciences but originates in observations and theoretical speculations from social and cultural anthropology. 


\section{Concluding remarks}

It has recently been argued that the cognitive and behavioral sciences have been too cavalier in seeking to generalize to humanity results of studies conducted mainly with Western, educated, industrialized, rich, and democratic ("Weird") societies, which are "among the least representative populations one could find for generalizing about humans" (Henrich, Heine, \& Norenzayan, 2010). If the problem were merely one of sampling, then it could be solved by more extensive replication of experiments in a greater diversity of human populations (Medin, Bennis, \& Chandler, 2010). But the problem goes deeper than that. Research agendas and the specific experimental designs to which they give rise are also shaped by the historically contingent assumptions and priorities of "Weird" societies. To take a general example, much developmental psychology likes to imagine children as little scientists, curiously exploring the physical affordances and causal structure of their environments by means of hypothesis testing (Gopnik, 2000). This perspective on its trajectory could readily be traced through the influential work of Jean Piaget and his intellectual heirs. But how would human development look from the perspective of more traditional cultures? Rapid technological innovation and scientific advance is a very modern phenomenon and social organization and cultural transmission in much of the world remains highly repetitive and tradition bound. Taking that latter perspective on social learning as our starting point would no doubt produce rather different research agendas in developmental psychology (Whitehouse, 2011). While cross-cultural psychology can help to address the "Weird" sampling issue, it offers no substitute for systematic documentation of variation in cultural systems. Using the problem of explaining cooperation as our principal example, we have made a case that ethnographic observation has a vital role to play in the formulation of research questions and agendas in the cognitive and behavioral sciences. Insofar as ethnography remains the principal method of social and cultural anthropology, exclusion of that discipline from the scientific study of our species would be a grave mistake.

\section{Acknowledgments}

This work was supported by an ESRC Large Grant (REF RES-060-25-0085) entitled "Ritual, Community, and Conflict"' (Whitehouse).

\section{References}

Atkinson, Q. D., \& Whitehouse, H. (2010). The cultural morphospace of ritual form; Examining modes of religiosity cross-culturally. Evolution and Human Behavior, 32 (1), 50-62.

Axelrod, R. (1984). The evolution of cooperation. New York: Basic Books.

Bjorklund, D. F. (2011). You've come a long way baby: A brief history of developmental and evolutionary psychology, SRCD Biennial Conference, Montreal.

Cohen, E., Ejsmond-Frey, R., Knight, N., \& Dunbar, R. (2010). Rowers' high: Behavioural synchrony is correlated with elevated pain thresholds. Biology Letters, 6 (1), 106-108. 
D’Andrade, R. G. (1995). The development of cognitive anthropology. Cambridge, England: Cambridge University Press.

Dawkins, R. (1976). The selfish gene. Oxford, England: Oxford University Press.

Gopnik, A. (2000). The scientist in the crib: What early learning tells us about the mind. London: HarperCollins Publishers.

Hamilton, W. D. (1964). The genetical evolution of social behaviour. Journal of Theoretical Biology, 7, 1-16.

Henrich, J., Heine, S. J., \& Norenzayan, A. (2010). The weirdest people in the world? Behavioral and Brain Sciences, 33, 61-135.

Hove, M. J., \& Risen, J. L. (2009). It's all in the timing: Interpersonal synchrony increases affiliation. Social Cognition, 27 (6), 949-960.

Johnson, K. (2004). Primary emergence of the doctrinal mode of religiosity — in prehistoric southwestern Iran. In H. Whitehouse \& L. H. Martin (Eds.), Theorizing religions past: Historical and archaeological-perspectives (pp. 45-66). Walnut Creek, CA: AltaMira Press.

Kertzer, D. I. (1989). Ritual, politics, and power. New Haven, CT: Yale University Press.

Kirschner, S., \& Tomasello, M. (2010). Joint music making promotes prosocial behavior in 4-year-old children. Evolution and Human Behavior, 31, 354-364.

Medin, D. L., Bennis, W. M., \& Chandler, M. (2010). Culture and the home-field disadvantage. Perspectives on Psychological Science, 5, 708-713.

Michod, R. E. (1999). Darwinian dynamics. Princeton, NJ: Princeton University Press.

Miles, L. K., Nind, L. K., Henderson, Z., \& Macrae, C. N. (2010). Moving memories: Behavioral synchrony and memory for self and others. Journal of Experimental Social Psychology, 46 (2), 457-460.

Mithen, S. (2004). From Ohalo to Çatalhöyük: The development of religiosity during the early prehistory of Western Asia, 20,000-7000 BC. In H. Whitehouse \& L. H. Martin (Eds.), Theorizing religions past: Historical and archaeological perspectives (pp. 17-43). Walnut Creek, CA: AltaMira Press.

Nowak, M. A. (2006). Five rules for the evolution of cooperation. Science, 314 (5805), 1560-1563.

Richert, R., Whitehouse, H., \& Stewart, E. E. A. (2005). Memory and analogical thinking in high-arousal rituals. In H. Whitehouse \& R. N. McCauley (Eds.), Mind and religion: Psychological and cognitive foundations of religiosity (pp. 127-145). Walnut Creek, CA: AltaMira Press.

Turner, V. (1969). The ritual process: Structure and anti-structure. Chicago: Aldine Publishing.

Turner, V. (2001). From ritual to theatre: The human seriousness of play. Boston: PAJ Books.

Whitehouse, H. (1995). Inside the cult: Religious innovation and transmission in Papua New Guinea. Oxford, England: Oxford University Press.

Whitehouse, H. (2000). Arguments and icons: Divergent modes of religiosity. Oxford, England: Oxford University Press.

Whitehouse, H. (2004). Modes of religiosity: A cognitive theory of religious transmission. Walnut Creek, CA: AltaMira Press.

Whitehouse, H. (2011). The coexistence problem in psychology, anthropology, and evolutionary theory. Human Development, 54, 191-199.

Whitehouse, H., \& Hodder, I. (2010). Modes of religiosity at Çatalhöyük. In I. Hodder (Ed.), Religion in the emergence of civilization: Çatalhöyük as a case study (pp. 122-145). Cambridge, England: Cambridge University Press.

Whitehouse, H., \& Martin, L. H. (Eds.) (2004). Theorizing religions past: Archaeology, history, and cognition. Walnut Creek, CA: AltaMira Press.

Wiltermuth, S. S., \& Heath, C. (2009). Synchrony and cooperation. Psychological Science, 20 (1), 1-5. 